\title{
Mars rover under pressure to reach mountain goal
}

\section{Curiosity's memory glitch prompts mission scientists to pick up the pace.}

\section{BY ALEXANDRA WITZE}

S even months after it hurtled to a landing on Mars, NASA's Curiosity rover has rolled just 738 metres across the surface. It remains about 10 kilometres from its primary goal: Aeolis Mons, a 5-kilometre-high mountain thought to contain layers formed in ancient ponds. With the mission nearly onethird of the way through its allotted two years, the science team is beginning to feel the pressure to get moving.

If Curiosity were to die tomorrow, "we could certainly say we achieved a lot", says scienceteam member Laurie Leshin, a planetary geochemist at Rensselaer Polytechnic Institute in Troy, New York. "But none of us would be satisfied."

It took two months just to unfurl the array of scientific instruments on the US $\$ 2.5$-billion Curiosity - the biggest, most expensive and most lavishly equipped rover ever sent to Mars. It is also planetary exploration's most complicated robot ever, with about 400 scientists working on ten different instruments: a social environment that can slow things down. But the first serious glitch of the mission - a memory malfunction on 28 February that forced operators to use the rover's backup computer - has reminded Curiosity's handlers that the machine is mortal.

From the start, however, mission scientists have found plenty of intriguing distractions. Soon after touching down in Gale Crater on 6 August last year, the rover found evidence of a dried-up stream bed near the base of Peace Vallis, an 80-square-kilometre fan of sediments that washed down from the walls of the crater.

In October, after heading to Glenelg, a junction where three terrains come together, the rover stopped for almost two months at a drift of sand dubbed Rocknest. Here, Curiosity plunged its sampling scoop into the sand and tipped the material into its two main analytical instruments, CheMin (for Chemistry and Mineralogy) and SAM (Sample Analysis at Mars). On 19 March, an entire session of the Lunar and Planetary Science Conference at the Woodlands, near Houston, Texas, was devoted to the findings at Rocknest. The dune turns

\section{ONATURE.COM} For more on the Mars Curiosity rover, see Nature's special: nature.com/curiosity

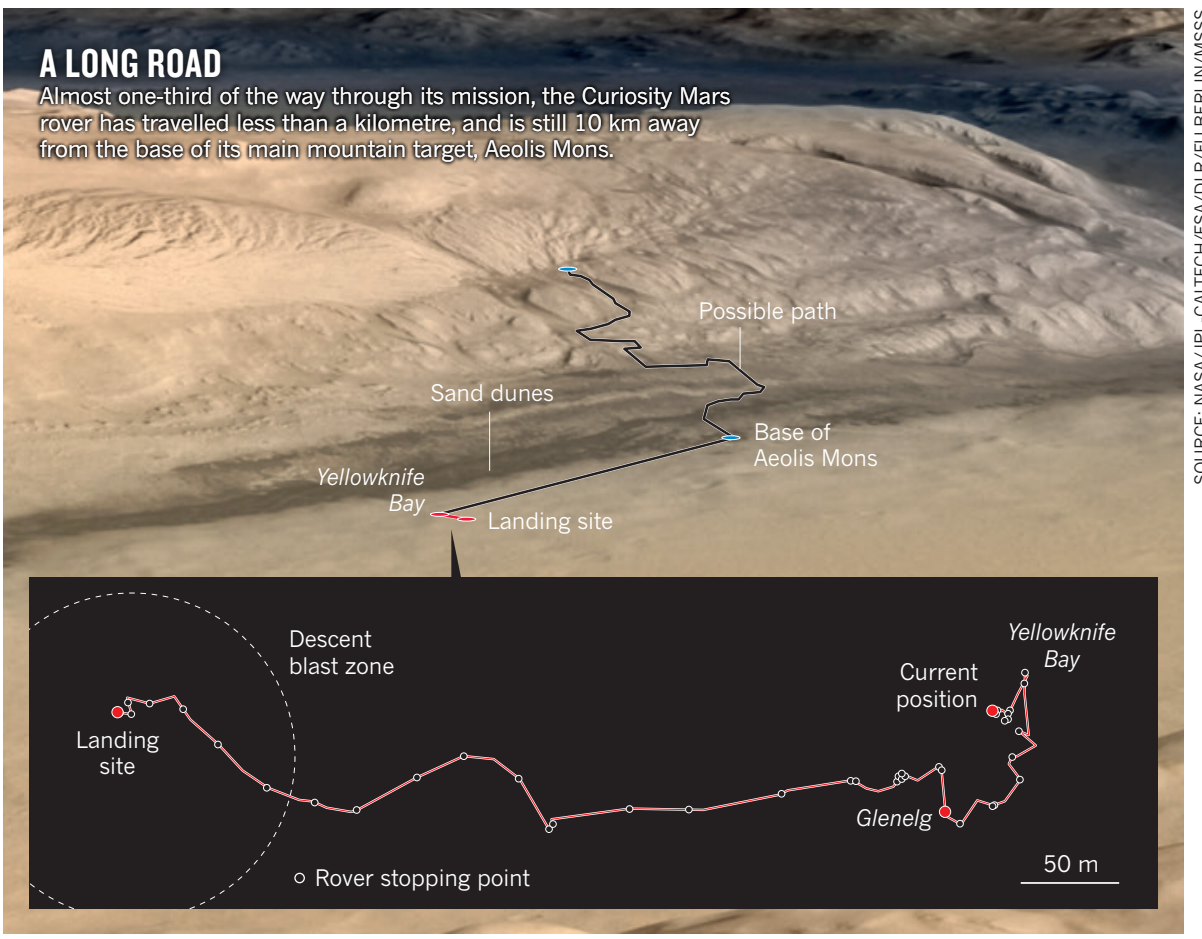

out to be chemically similar to soils analysed elsewhere on Mars, suggesting that materials such as water move between the soil and atmosphere in similar ways around the planet.

Also at the conference, scientist Chris Webster of NASA's Jet Propulsion Laboratory in Pasadena, California, reported the latest on methane measurements taken by the rover's atmosphere-sniffing, tunable laser spectrometer. The spectrometer team's findings have lowered the upper limit for methane in Mars's atmosphere - to as little as 3 parts per billion by volume. The scarcity of methane casts doubt on the possibility that Martian microbes are emitting the gas into the atmosphere (see Nature 491, 174; 2012). The instrument has been used just three times in the first 200 sols (Martian days), even though it can be activated at night when there is less demand from other science instruments on the rover. This is a sign of the intense competition for rover time: one of the reasons for the slow pace.

Since 23 January, the rover has more or less stayed in one place, snuggled up next to a reddish rock nicknamed John Klein, in a region called Yellowknife Bay. At John Klein, Curiosity used its drill for the first time, and analysis of the powdered drilling sample revealed clay minerals that formed in a watery environment, along with oxidized and reduced forms of sulphur. That suggests that Yellowknife Bay was once a benign environment for microbial life (see Nature http://doi.org/ktt; 2013). Yellowknife "has been a great place to start", says team member Roger Wiens of Los Alamos National Laboratory in New Mexico. "We wouldn't have wanted to miss this for anything."

But Jorge Vago, project scientist for the European Space Agency's ExoMars mission, says that he is already thinking about how he will need to do things faster with his rover, which is scheduled for launch in 2018. "Clearly, we couldn't afford to run ExoMars in the way [Curiosity] is doing the mission," he says. Instead, ExoMars is likely to have a shorter mission length, so might need to perform its science at a pace somewhere between the tortoise speed of Curiosity and the hare-like rate of NASA's Spirit and Opportunity rovers, which landed on Mars in 2004 with primary missions of a little over three months.

Just as Curiosity's science team is getting 
itchy to move the rover again, however, it will have to take another long break. For most of April, Mars will be behind the Sun as seen from Earth, and no spacecraft on or around Mars will be able to radio home. After Mars emerges, the team aims to drill into the John
Klein rock once more, to repeat the measurements. Then the rover will finally hit the road to Aeolis Mons, also known as Mount Sharp.

Curiosity will follow a seemingly flat, unobstructed path around a set of sand dunes (see 'A long road') at speeds of up to 100 metres a day, says Raymond Arvidson, a planetary geologist at Washington University in St Louis, Missouri. "I call it the rapid transit route," says Arvidson. "There's general agreement that we have to get to the base of Mount Sharp before the primary mission ends, with a lot of time to spare."

\section{Gene-analysis firms reach for the cloud}

\section{Online bioinformatics companies rush to provide genomics platforms and software for hospitals.}

\section{BY ERIKA CHECK HAYDEN}

$\mathrm{F}$ or Chaim Jalas at the Center for Rare Jewish Genetic Disorders in New York, DNA sequencing is the easy part. It costs less than US $\$ 1,500$ per person to have the important parts of his clients' genomes sequenced. But it would be dauntingly expensive to maintain servers and staff to analyse the data and identify mutations that might be causing the undiagnosed diseases that afflict his clients' families.

So Jalas, the centre's director of genetics resources and services, has outsourced parts of the analysis. He uploads his clients' sequencing data to cloud-computing software platforms, where he can run analyses without having to set up the infrastructure in-house. The cost is about $\$ 100$ per person. And the cloud-based interfaces let him collaborate with doctors in Israel without worrying about repeatedly transferring data on slow Internet connections. "For me, it is convenient and cost-efficient," he says.

Jalas and the way he works represent a new and mostly untapped market for a new crop of genetics interpretation and analysis firms, which will be touting for customers at a meeting of the American College of Medical Genetics and Genomics in Phoenix, Arizona, on 19-23 March. Dozens of these firms have emerged, some in the past year, as ever more affordable sequencing moves from academia into the clinic (see Nature 494, 290-291; 2013). Doctors will increasingly want to use sequencing data to guide decisions about patient care, but might not necessarily want to invest in staff and software to make sense of those data.

"It's a huge unmet need," says David Ferreiro, a biotechnology analyst with investment bank Oppenheimer \& Company in New York, which invests in many sequencing-technology and -analysis companies.

Where there is a need, there is also money to be made. The companies, many of them based in California's Silicon Valley, have been tempted by a market in outsourced sequencing and analysis software that by 2016 could top $\$ 4$ billion per year, according to BCC Research, a marketresearch company in Wellesley, Massachusetts (See 'Genes in the marketplace'). “The sky's the limit," says Andreas Sundquist, chief executive of DNAnexus in Mountain View, California, which provides genetic-analysis software on its cloud-based platform and allows users to upload and run their own algorithms.

Other firms offer a range of approaches. Seven Bridges Genomics, based in Cambridge, Massachusetts, aims to be accessible to people with no expertise in bioinformatics, and provides access to free tools for designing custommade analysis pipelines. Ingenuity Systems in Redwood City, California, allows users to upload a list of mutations in a person's genome, and finds those most likely to cause disease. Personalis, down the road in Menlo Park, offers sequencing services and interpretation for clinicians and pharmaceutical and biotechnology companies. Last week, the company won a \$1.53-million contract with the US Department of Veterans Affairs to look for genetic variants

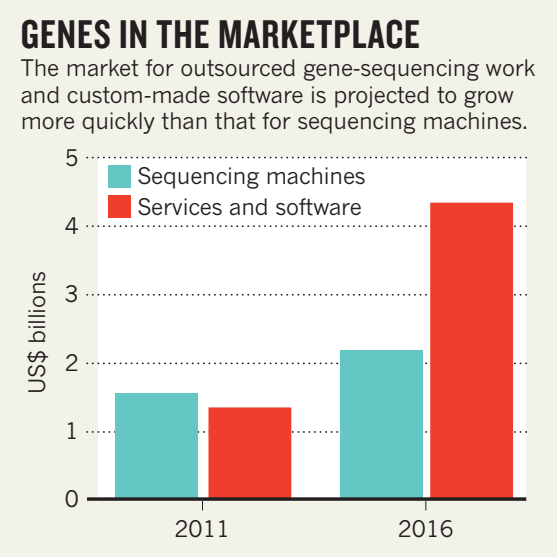

in samples from as many as one million military veterans, to explore the variants' roles in disease. (The company will outsource the sequencing to Illumina, a market leader in sequencing technology based in San Diego, California.)

The activity is reminiscent of that a decade ago, when bioinformaticians started up a flurry of companies, most of which were unsuccessful because the path from a genetic-disease marker to a profitable drug has not been straightforward. Today's companies have moved on to other challenges, says Steven Brenner, a computational genomicist at the University of California, Berkeley. He says that they will have to prove that their products are better than freely available software - and do so without disclosing their intellectual property. "These companies have a tricky situation," he says.

And they are facing competition from the sequencing-technology firms themselves. Last year, Illumina opened BaseSpace Apps, a marketplace for online analysis tools to be used on data uploaded to the company's own cloud-computing platform. Information-technology companies are getting in on the action, too: Oracle, based in Redwood Shores, California, has its own products aimed at helping researchers and hospitals to analyse data.

But one of the biggest questions will be how deeply analysis companies can reach into medical settings, where privacy concerns are paramount. Hospitals can be fined if patient privacy is compromised, and clinical geneticists may be uneasy about uploading data to the cloud. "It's your licence and your lab that go on the line when it comes to reporting a clinical result," says Elizabeth Worthey, director of genomic informatics at the Human and Molecular Genetics Center at the Medical College of Wisconsin in Milwaukee. That is a large part of why many hospitals have so far chosen to build their own analysis infrastructure, says Ferreiro.

To address privacy concerns, Bina Technologies in Redwood City sells a server that can sit in a customer's own data centre and is optimized to run genome-analysis software. Knome of Cambridge, Massachusetts, announced last year that it plans to sell $\$ 125,000$ genome-analysis machines for use in customers' labs (see Nature 490, 157; 2012).

It seems unlikely that any single analysis company will rule the market; the range of customers who need to interpret sequence data is growing, and each has their own needs. "We would rather see a thousand flowers bloom," says Sundquist. "I don't think we're going to see consolidation anytime soon." - 